\title{
Synthesis and Characterization of Activated Carbon Foam from Polymerization of Furfuryl Alcohol Activated by Zinc and Copper Chlorides
}

\author{
Elisabetta M. Cepollaro ${ }^{1,2}$, Domenico Caputo ${ }^{1,3,4}$, Stefano Cimino ${ }^{2}\left(\mathbb{D}\right.$, Nicola Gargiulo ${ }^{1,5}$ (D) \\ and Luciana Lisi ${ }^{2, *}$ \\ 1 ACLabs-Applied Chemistry Labs, Department of Chemical, Materials and Industrial Production \\ Engineering, University of Naples Federico II, P.le V. Tecchio 80, 80125 Naples, Italy; \\ elisabettamaria.cepollaro@unina.it (E.M.C.); domenico.caputo@unina.it (D.C.); ngargiul@unina.it (N.G.) \\ 2 Istituto di Ricerche sulla Combustione, CNR, P. le V. Tecchio 80, 80125 Naples, Italy; stefano.cimino@cnr.it \\ 3 CeSMA-Centro di Servizi Metrologici e Tecnologici Avanzati, University of Naples Federico II, \\ Corso N. Protopisani, 80146 Naples, Italy \\ 4 INSTM Research Unit @ University of Naples Federico II, P.le V. Tecchio 80, 80125 Naples, Italy \\ 5 Centro Regionale di Competenza (CRdC) Tecnologie Scarl, Via Nuova Agnano 11, 80125 Naples, Italy \\ * Correspondence: luciana.lisi@cnr.it
}

Received: 15 June 2020; Accepted: 3 July 2020; Published: 7 July 2020

\begin{abstract}
Polymerization of furfuryl alcohol carried out using $\mathrm{ZnCl}_{2}$ or $\mathrm{CuCl}_{2}$ as Lewis acid activators was investigated by exploring various synthesis parameters in order to produce activated carbons with different porosity and metal load. The temperature of polymerization was changed according to Lewis acidity strength of the two metal chlorides: $0{ }^{\circ} \mathrm{C}$ for $\mathrm{CuCl}_{2}$ and $80{ }^{\circ} \mathrm{C}$ for $\mathrm{ZnCl}_{2}$. The polymer obtained was pyrolyzed under pure He flow or under $1000 \mathrm{ppm} \mathrm{O}_{2} / \mathrm{He}$ flow at 600 or $850{ }^{\circ} \mathrm{C}$ in order to produce activated carbons with specific textural features. The load and nature of the residual metal after pyrolysis were determined by ICP and XRD analyses, respectively. Copper was mostly preserved even at high pyrolysis temperature in contrast to zinc, which was almost totally lost at $850{ }^{\circ} \mathrm{C}$. A foamy structure was detected by SEM analysis for all samples. Textural properties were determined by both $\mathrm{N}_{2}$ and $\mathrm{CO}_{2}$ physisorption; surface areas and pore size distributions were evaluated according to BET, DFT and DR models. The polymerization activated by $\mathrm{ZnCl}_{2}$ produced carbons with larger surface areas were also related to the presence of some mesopores, whereas $\mathrm{CuCl}_{2}$ promoted the prevailing formation of narrow micropores, making these materials particularly suited to $\mathrm{H}_{2}$ storage applications.
\end{abstract}

Keywords: activated carbon; adsorption; furfuryl alcohol; polymerization; Lewis acid metals; narrow micropores

\section{Introduction}

Micro- and meso-porous carbons are widely employed in a lot of applications ranging from molecular sieve and gas storage up to catalysis [1,2]. To optimize the sorption capacity of carbons, the morphological and textural features must be suitably designed [3,4]. Indeed, a tailored porosity is often necessary for specific applications such as hydrogen storage requiring a high value of micropore volume to achieve large hydrogen storage capacity at room temperature [3,5].

Carbon materials are lighter than inorganic compounds, which represents an advantage for storage systems [6]. Most of carbons are obtained as powders, which limits their applicability when macroscopic morphologies are required [2]. Nevertheless, activated carbon in a structured form is not attainable due to the difficult cohesion of carbon powder particles requiring the use of 
ligands. Lozano-Castelló et al. [7] investigated a quite large number of binders to prepare cylindrical shaped activated carbons and found that, although all binders provide good mechanical properties, the adsorption capacity of the activated carbon monolith was reduced compared to that of the starting carbon material due to the partial blocking of porosity. The extent of micropore blocking depends on the type of binder. Commercially activated carbon monoliths are also available, consisting of a carbon layer on a ceramic substrate with a limited adhesion and a loading of about $50 \%$. The activated carbon layer necessarily contains some binder.

For this reason, the template synthesis of porous carbon using a replica technique has attracted a lot of interest in the last two decades [8,9], in particular nanocasting of carbon replica on siliceous porous materials. The application of this technique allows a proper modulation of textural properties, tailored to the final use [3]. According to this method, silica with interconnected porosity is impregnated with a carbon precursor, which is then pyrolyzed in order to obtain the activated carbon. After dissolution of the silica framework, a porous ordered carbon foam is obtained representing the negative replica of the starting template $[8,9]$.

Nevertheless, the hard-templating method involves a quite complex preparation procedure including the preparation of the nanostructured silica template, the impregnation with the carbon precursor, the pyrolysis of the precursor and the etching of the templates with HF solution [8]. To avoid the necessity for several washing treatments after the etching step, Zhang et al. [9] proposed $\mathrm{NaOH}$ etching of the carbon-silica templates followed by filtration and drying, thus obtaining an alkaline mesoporous carbon with high performance in $\mathrm{H}_{2} \mathrm{~S}$ adsorption at room temperature, due to the introduction of basic properties greatly enhancing the sorption capacity of the acid.

One of the most common carbon precursors, furfuryl alcohol (FA), is generally introduced into silica pores together with oxalic acid which represents the polymerization catalyst [8]. Polymerization of FA is also activated by mineral acids $\left(\mathrm{H}_{2} \mathrm{SO}_{4}\right.$, etc.), organic acid ( $p$-toluenesulphonic, etc.), acid zeolites (HY, HZSM5) and Lewis acid $\left(\mathrm{I}_{2}, \mathrm{SnCl}_{4}, \mathrm{TiCl}_{4}\right)$ [10]. Cesano et al. [10] proposed for the first time $\mathrm{ZnCl}_{2}$ as an acid promoter for FA polymerization at $60-70{ }^{\circ} \mathrm{C}$ to obtain porous $\mathrm{ZnO}$-carbon composites characterized by a uniform layer of highly dispersed $\mathrm{ZnO}$ crystallites on the surface of the carbon matrix or, at high pyrolysis temperatures, of a pure carbon phase containing holes whose distribution and size is driven by the $\mathrm{Zn}$ content.

Wei et al. [11] also studied $\mathrm{ZnO}$-porous carbon composites starting from $\mathrm{FA} / \mathrm{ZnCl}_{2} /$ water solution used to dip-coat glass mats focusing on the effect of the pyrolysis time at $450{ }^{\circ} \mathrm{C}$ on the morphology of $\mathrm{ZnO}$ crystals more than on that of the carbon matrix.

It has been reported that the introduction of transition metals or metal oxides particles into carbon nanotubes enhances the hydrogen storage capacity [12]. Furthermore, the addition of gold, nickel, copper, or palladium strongly increases the electrochemical storage of $\mathrm{H}_{2}$ on carbons [13].

The good promoting effect of both zinc and copper finely dispersed on activated carbon granular particles at room temperature was recently also demonstrated for $\mathrm{H}_{2} \mathrm{~S}$ adsorption [14-16].

The work of Cesano et al. [10,17] suggested the possibility of dispersing the metal promoters directly during the synthesis of activated carbon, producing a material that could potentially be used in gas storage.

On the basis of this consideration, in this paper, we explored the possibility of also introducing another metal, i.e., copper, that can potentially act as a Lewis acid activator for polymerization of furfuryl alcohol in order to produce activated carbons with special adsorption features determined not only by the textural properties, but also by the presence of a given metal, by suitably tuning the polymerization conditions. $\mathrm{ZnCl}_{2}$ was also investigated as a promoter of FA polymerization, in order to have a direct comparison with the Cu-activated material.

Furthermore, a simple preparation method, avoiding the common complex and long multi-step procedure generally used to produce activated carbon as foam monoliths, is investigated. In other words, this paper provides a methodology to produce activated carbons with a tailored porosity and 
metal load, required by the specific adsorption application, as foamy monoliths potentially usable for high pressure processes such as gas storage.

\section{Materials and Methods}

\subsection{AC Synthesis}

High-purity (98\%) furfuryl alcohol (FA) supplied by Sigma Aldrich (Milan, Italy) was used as starting material for polymerization. $\mathrm{ZnCl}_{2}$ (RPE-Carlo Erba (Milan, Itay), $98 \%$ purity) and $\mathrm{CuCl}_{2}$ (Aldrich (Milan, Italy), >99\% purity) were used as Lewis acids to activate the FA polymerization. The low solubility of the two chlorides in FA caused a rapid FA polymerization taking place on the external surface of granules of metal salt creating a poly furfuryl alcohol (PFA) compact layer which inhibits the further occurrence of the reaction due to the hard penetration of FA towards the salt particles core. For this reason, for both metals an amount corresponding to the desired load in the FA precursor was preliminarily dissolved in a suitable volume of water that was then added to FA.

$\mathrm{Zn} / \mathrm{AC}$ sample was prepared starting from $5.67 \mathrm{~g} \mathrm{ZnCl}_{2}$ dissolved in $1.5 \mathrm{~mL}$ water (solubility $\mathrm{ZnCl}_{2}=4.32 \mathrm{~g} / \mathrm{mL}$ ), which was added to $24.45 \mathrm{~mL}$ of FA in order to obtain $17 \mathrm{wt} . \% \mathrm{ZnCl}_{2}$ concentration in the PFA. A lower fraction of copper chloride was used due to the high Lewis acid strength of copper ion; $2.33 \mathrm{~g} \mathrm{CuCl}_{2}$ was dissolved in $3 \mathrm{~mL}$ water and then added to $27.5 \mathrm{~mL}$ FA. The final expected concentration of copper chloride in the PFA was $7 \mathrm{wt} . \%$.

The FA-metal chloride water solution was then stirred, keeping a constant temperature ranging from 0 to $80^{\circ} \mathrm{C}$. The initial light brown colour of the solution becomes darker and darker and the viscosity slowly increased. Then, in some cases, a very quick formation of a foam coupled to a large increase of initial volume took place, depending on the temperature and the nature of the metal, which will be described in detail below.

The solid-like PFA was then pyrolyzed under pure $\mathrm{He}$ or $1000 \mathrm{ppm}_{2} / \mathrm{He}$ mixture, heating to 600 or $850^{\circ} \mathrm{C}$ at $5{ }^{\circ} \mathrm{C} / \mathrm{min}$ for $3 \mathrm{~h}$. $\mathrm{O}_{2}$ traces in the gas mixture were added in some pyrolysis steps in order to verify the possible formation of metal oxides (more thermally stable in the case of zinc), as suggested by Cesano et al. [10], but also to investigate whether $\mathrm{O}_{2}$ traces could affect the porosity causing a limited carbon burning that could potentially open or widen some pores.

\subsection{Sample Characterization}

Pyrolysis of PFA was investigated by simulating the process in a Setaram Labsys Evo (Caluire, France) thermobalance by increasing the temperature up to $850{ }^{\circ} \mathrm{C}$ at $5{ }^{\circ} \mathrm{C} / \mathrm{min}$ under pure $\mathrm{N}_{2}$.

The morphology of the AC samples and the metal distribution were investigated by SEM/EDX FEI (Hillsboro, OR, US) Inspect instrument equipped with an energy dispersive X-ray probe.

The actual zinc and copper content in the AC samples was verified with ICP-MS analysis using an Agilent 7500 (Milan, Italy) instrument after MW-assisted dissolution of the samples in $\mathrm{HCl} / \mathrm{HF} / \mathrm{H}_{2} \mathrm{O}_{2}$ (4/1/1 volume) solution.

X-ray diffraction (XRD) of powdered samples was performed by means of a Philips X'Pert PRO (Cambridge, UK) apparatus (working radiation $\mathrm{CuK} \alpha$, anti-scatter silt width: $7.5 \mathrm{~mm}$ ); the $2 \theta$ range of collected patterns was $5-100^{\circ}$, which was scanned using a step size of $0.013^{\circ}$ and a scan speed of $0.156^{\circ} \mathrm{s}^{-1}$.

Raman spectra were recorded using a Horiba XploRA Raman microscope system (Horiba Jobin Yvon, Kyoto, Japan) with an excitation wavelength of $\lambda=532 \mathrm{~nm}$ (frequency doubled Nd:YAG-solid state laser, $25 \mathrm{~mW}$ ) in the range $500-4000 \mathrm{~cm}^{-1}$ (Stokes Raman shift).

The surface area and the pore volume of all AC samples after pyrolysis were evaluated by $\mathrm{N}_{2}$ physisorption at $77 \mathrm{~K}$ using a Quantachrome Autorsorb 1C (Boynton Beach, FL, US) gas porosimeter after degassing the samples at $150{ }^{\circ} \mathrm{C}$ for $4 \mathrm{~h}$. Surface area was estimated according to BET, DFT and DR models. Pore volume was evaluated according to both DFT and DR models. Even though the BET model was originally formulated for calculating the specific surface area of materials that give IUPAC 
Type II or Type IV isotherms, it is usually also employed to provide an appraisal of the specific surface area of materials, like activated carbons, which generally give Type I isotherms [18]. DFT was applied using a typical kernel for carbon materials having slit pore geometry [19]. The DR model was chosen for providing an estimation of the micropore volume and the corresponding surface area [20]. Due to the presence of an open hysteresis loop, suggesting the presence of narrow micropores and/or bottle neck pores [21,22], additional textural characterization was carried out through $\mathrm{CO}_{2}$ adsorption at $273 \mathrm{~K}$ by means of a Micromeritics ASAP 2020 (Norcross, GA, US) instrument. In this case, all samples were preliminarily degassed for $3 \mathrm{~h}$ at $150{ }^{\circ} \mathrm{C}$ for free space measurements and then re-degassed for $9 \mathrm{~h}$ at the same temperature for isotherm measurements.

\section{Results and Discussion}

$\mathrm{Zn} / \mathrm{AC}$ sample. A $\mathrm{Zn} / \mathrm{AC}$ sample was prepared stirring the $\mathrm{FA}-\mathrm{ZnCl}_{2}$ water solution at different temperatures. The mixture required several days to reach a highly viscous texture at room temperature. Cesano et al. [17] reported that, at room temperature, a time $>12 \mathrm{~h}$ was necessary to obtain PFA, whereas in our experiment at room temperature a highly viscous material was obtained after times as long as 10 days.

For this reason, another synthesis keeping the same composition of the mixture was performed, increasing the temperature to $80{ }^{\circ} \mathrm{C}$. Under this condition, after about $40 \mathrm{~min}$, an instantaneous formation of a foamy polymer occurred, as shown in Figure 1. This was considered a positive event. Actually, this could represent an easy and rapid method for producing a structured activated carbon.

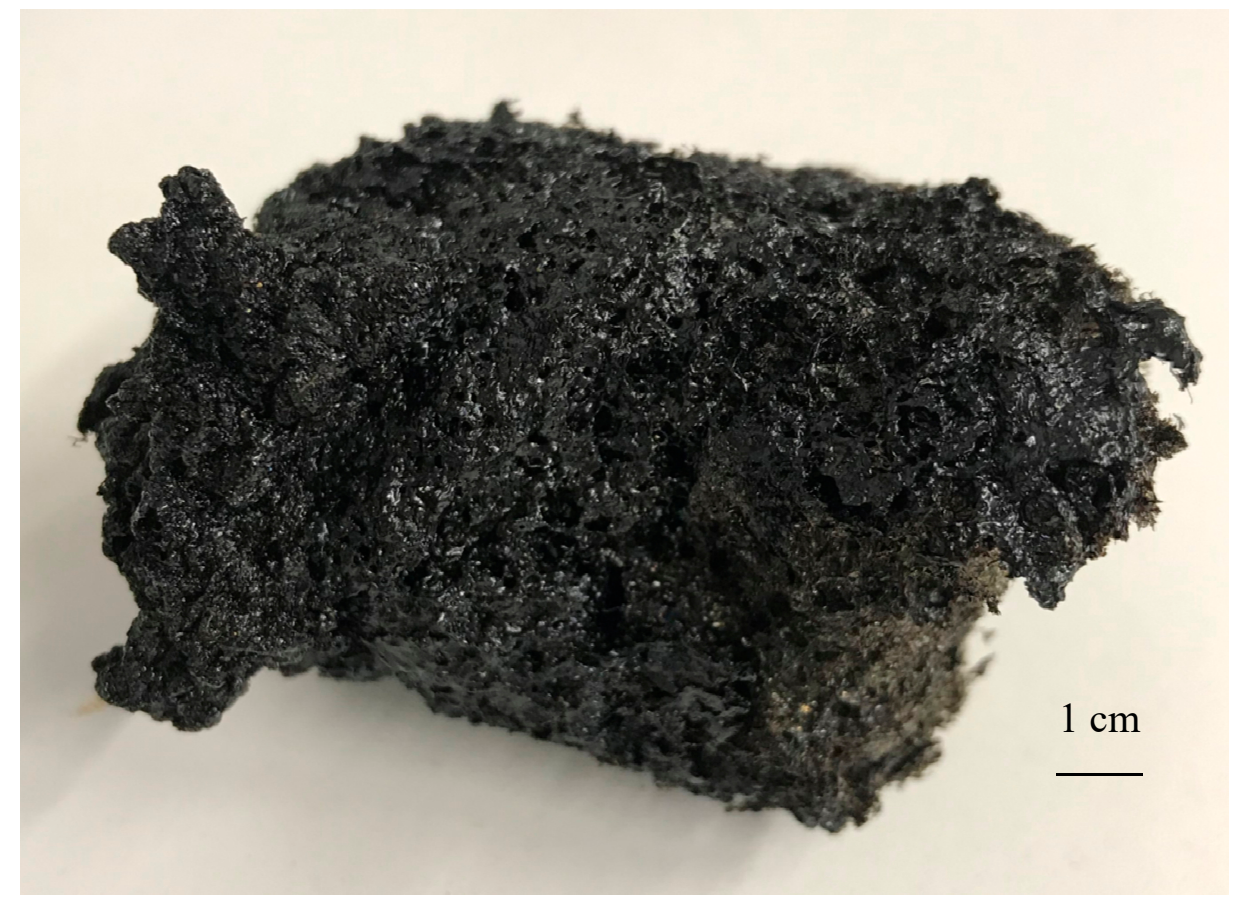

Figure 1. Picture of foamy PFA obtained from $\mathrm{Zn}$-activated polymerization of FA at $80{ }^{\circ} \mathrm{C}$.

$\mathrm{Cu} / \mathrm{AC}$ sample. $\mathrm{Cu}^{2+}$ is a stronger Lewis acid than $\mathrm{Zn}^{2+}$ because of its smaller ionic radius and the higher Pauling electronegativity. As a consequence, a stronger activation of branching and cross-linking can be expected. For this reason, a lower $\mathrm{CuCl}_{2}$ concentration $(7 \mathrm{wt} \%)$ was chosen in order to balance the stronger Lewis acid strength of copper chloride with respect to zinc chloride. Indeed, although an absolute classification of metal Lewis acids is not possible because the acidity value strongly depends on the reaction, Kobayashi et al. [23] classified the Lewis acidity of many metal chlorides on the basis of yield and selectivity in the addition reaction of silyl enolate to an aldehyde and an aldimine. 
They found $60 \%$ yield for $\mathrm{CuCl}_{2}$ and $23 \%$ yield for $\mathrm{ZnCl}_{2}$. The ratios between the concentration of the two metal chlorides we used was the same as these yields.

Nevertheless, despite the reduction of copper chloride concentration with respect to that of the zinc salt, FA polymerization took place with the formation of the polymer at room temperature in only two hours, compared to the several days required for $\mathrm{Zn}$-activated polymerization at the same temperature, coupled to a violent and uncontrolled formation of carbon foam. The same occurred at $80^{\circ} \mathrm{C}$ in only a few minutes. For this reason, FA was polymerized at $0{ }^{\circ} \mathrm{C}$, a condition that allowed a mild and controlled polymerization that occurred in 3 days.

These results show that the temperature of polymerization strongly influences the reaction time, and that if the cation is a stronger Lewis acid the temperature necessary to obtain the polymerization in a given time shifts to lower values. Of course, experimental conditions must be carefully chosen to carry out a controlled formation of foamy PFA.

The first explanation of the phenomenon of rapid polymerization of the FA was given by Dunlop and Peters [24]. They proposed a scheme of two simultaneous reactions occurring during the polymerization of FA in acid aqueous solutions, both involving the condensation of the $\mathrm{OH}$ groups. Then, branching and cross-linking can take place, and the rate at which these reactions occur increases with the formation of oligomers. By increasing branching and cross-linking, the liquid solution become more viscous and darker. The formation of foamy polymers goes through a gelly phase. Vaporization of water produced from branching and cross-linking due to the exothermal character of these reaction likely creates the cavities of the PFA foam.

It must be noted that, under our conditions, the presence of water different from that produced by the polymerization reactions, introduced from the very beginning into FA for the dissolution of the metal chlorides, can contribute to the formation of a foamy material, rapidly evaporating when the exothermal reactions take place.

Due to the too long time required to polymerize at room temperature for the $\mathrm{Zn}$-activated system and to the uncontrolled polymerization of the $\mathrm{Cu}$-activated system at 25 and $80^{\circ} \mathrm{C}$, characterization was done on PFA obtained at 80 and $0{ }^{\circ} \mathrm{C}$ for $\mathrm{ZnCl}_{2}$ and $\mathrm{CuCl}_{2}$ activation, respectively.

In Figure 2 the results of TG analysis carried out on both $\mathrm{Zn}$ - and $\mathrm{Cu}-\mathrm{PFA}$ under $\mathrm{N}_{2}$ are reported.

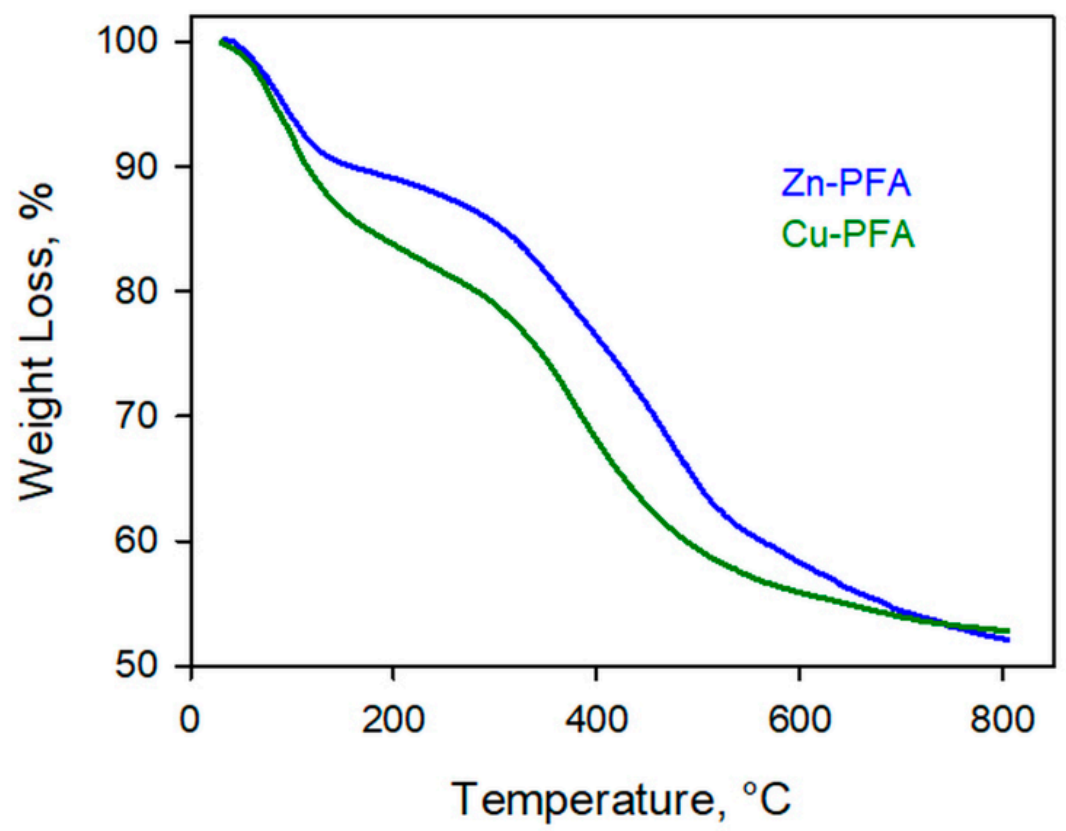

Figure 2. Weight loss as a function of temperature of $\mathrm{Zn}$ - and $\mathrm{Cu}$-activated PFA under $\mathrm{N}_{2}$ flow. 
Both samples undergo two main weight losses. The first, at $\mathrm{T}<150{ }^{\circ} \mathrm{C}$, was attributed to the sample dehydration, whereas the second, in the range $350-550{ }^{\circ} \mathrm{C}$, was attributed to PFA degradation leading to the formation of carbon $[25,26]$.

On the basis of these results, $600{ }^{\circ} \mathrm{C}$ was considered a temperature sufficient to pyrolyze PFA. Nevertheless, some samples were also pyrolyzed at $850{ }^{\circ} \mathrm{C}$ to investigate the effect of the temperature on the final properties of the activated carbon. As reported in the Experimental section, this final step was carried out under pure helium flow or under $1000 \mathrm{ppm} \mathrm{O}_{2} / \mathrm{He}$ mixture, as proposed by Cesano et al. [10].

In Table 1, a list of all samples is reported, with temperature of pyrolysis and composition of pyrolysis gas. The samples are labelled as Me/AC-T, where Me represents the metal, AC the activated carbon and $\mathrm{T}$ the temperature of pyrolysis. An asterisk, when present, indicates the presence of $\mathrm{O}_{2}$ in the pyrolysis gas.

Table 1. List of ACs with the preparation conditions.

\begin{tabular}{ccc}
\hline Samples & T(Pyrolysis) & Gas Composition(Pyrolysis) \\
\hline Zn/AC-600 & $600^{\circ} \mathrm{C}$ & $\mathrm{He}$ \\
$Z n / A C-850$ & $850^{\circ} \mathrm{C}$ & $\mathrm{He}$ \\
Cu/AC-850 & $850^{\circ} \mathrm{C}$ & $\mathrm{He}$ \\
$Z n / A C-600^{*}$ & $600^{\circ} \mathrm{C}$ & $1000 \mathrm{ppm} \mathrm{O}_{2} / \mathrm{He}$ \\
$Z n / A C-850^{*}$ & $850^{\circ} \mathrm{C}$ & $1000 \mathrm{ppm} \mathrm{O}_{2} / \mathrm{He}$ \\
Cu/AC-850* & $850^{\circ} \mathrm{C}$ & $1000 \mathrm{ppm} \mathrm{O}_{2} / \mathrm{He}$ \\
\hline
\end{tabular}

In Figure 3a the SEM image of $\mathrm{Zn} / \mathrm{AC}-850$ is shown in which the foamy structure of AC is easily visible. A similar structure, even if less "open", was also observed for Cu/AC-850 (Figure 3b).
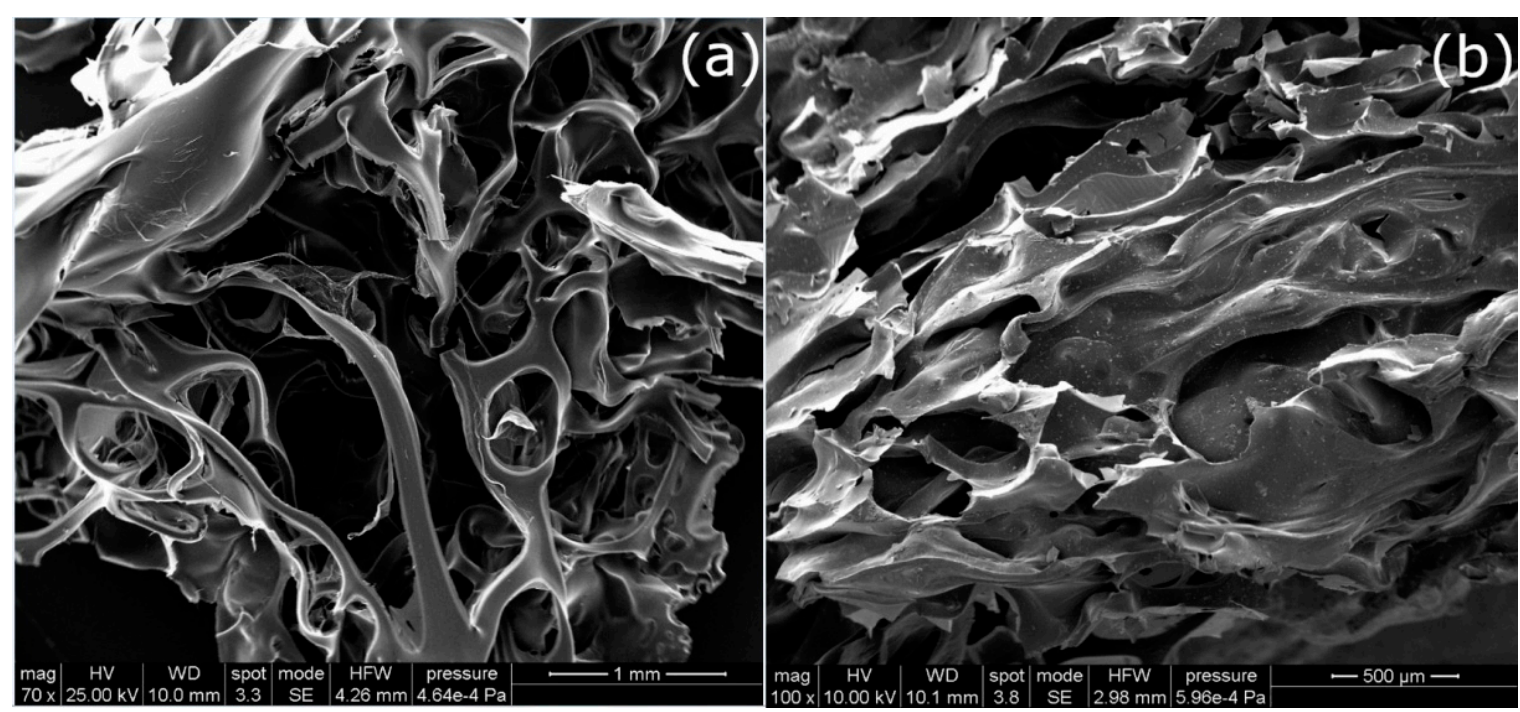

Figure 3. SEM images of $\mathrm{Zn} / \mathrm{AC}-850$ (a) and $\mathrm{Cu} / \mathrm{AC}-850$ (b)

A greater magnification highlights the presence of spherical particles on the carbon surface for both $\mathrm{Cu} / \mathrm{AC}-850$ and $\mathrm{Cu} / \mathrm{Ac}-600$ (Figure 4b), whereas needle-like particles, observed for Zn/AC-600 sample (Figure 4a) disappeared when the pyrolysis was carried out at $850{ }^{\circ} \mathrm{C}$ for the $\mathrm{Zn}$-activated sample.

The coupled EDX analysis confirmed that the particles detected were made of copper and zinc, respectively.

Results of ICP-MS analysis, carried out for all samples in various places of the foams to determine the actual metal content, are reported in Table 2. The values reported in the Table represent average contents, which changed by 13 and 15\% for copper and zinc, respectively, when moving from one 
sample portion to another. In the same table, the nominal metal content is also reported (first column) in order to evaluate the fraction of metal preserved upon the thermal treatment. For Zn-based materials, all values were much lower than the nominal one. On the contrary, copper load was quite close to the nominal one, although this sample was treated at $850{ }^{\circ} \mathrm{C}$. This result was expected for the $\mathrm{Zn}$-activated PFA pyrolyzed at $850{ }^{\circ} \mathrm{C}$ due to the lower temperature of evaporation of metallic $\mathrm{Zn}$ with respect to metallic $\mathrm{Cu}$ leading to the complete disappearance of the metal in both $\mathrm{Zn}$ samples. This is in agreement with results reported by Cesano et al. [10] who found by XANES experiments that Zn concentration decreased of about $50 \%$ in the samples treated at $600{ }^{\circ} \mathrm{C}$ and about $90 \%$ in the samples treated at $800{ }^{\circ} \mathrm{C}$ with respect to the supposed initial concentration in the PFA. The authors assumed that reduction of $\mathrm{Zn}$ (II) to metallic $\mathrm{Zn}$ occurred in the temperature range $400-800{ }^{\circ} \mathrm{C}$ that easily evaporates due to the high volatility. The evaporation of metallic zinc at $\mathrm{T}>800{ }^{\circ} \mathrm{C}$, also if starting from its oxide, was also found by other authors $[27,28]$. Nevertheless, the very low $\mathrm{Zn}$ concentration, also for the sample treated at $600{ }^{\circ} \mathrm{C}$, can probably be explained with some confinement on the outer surface of the metal during the fast PFA foam formation. This external portion of PFA foam was, however, removed in all cases without undergoing any subsequent pyrolysis.

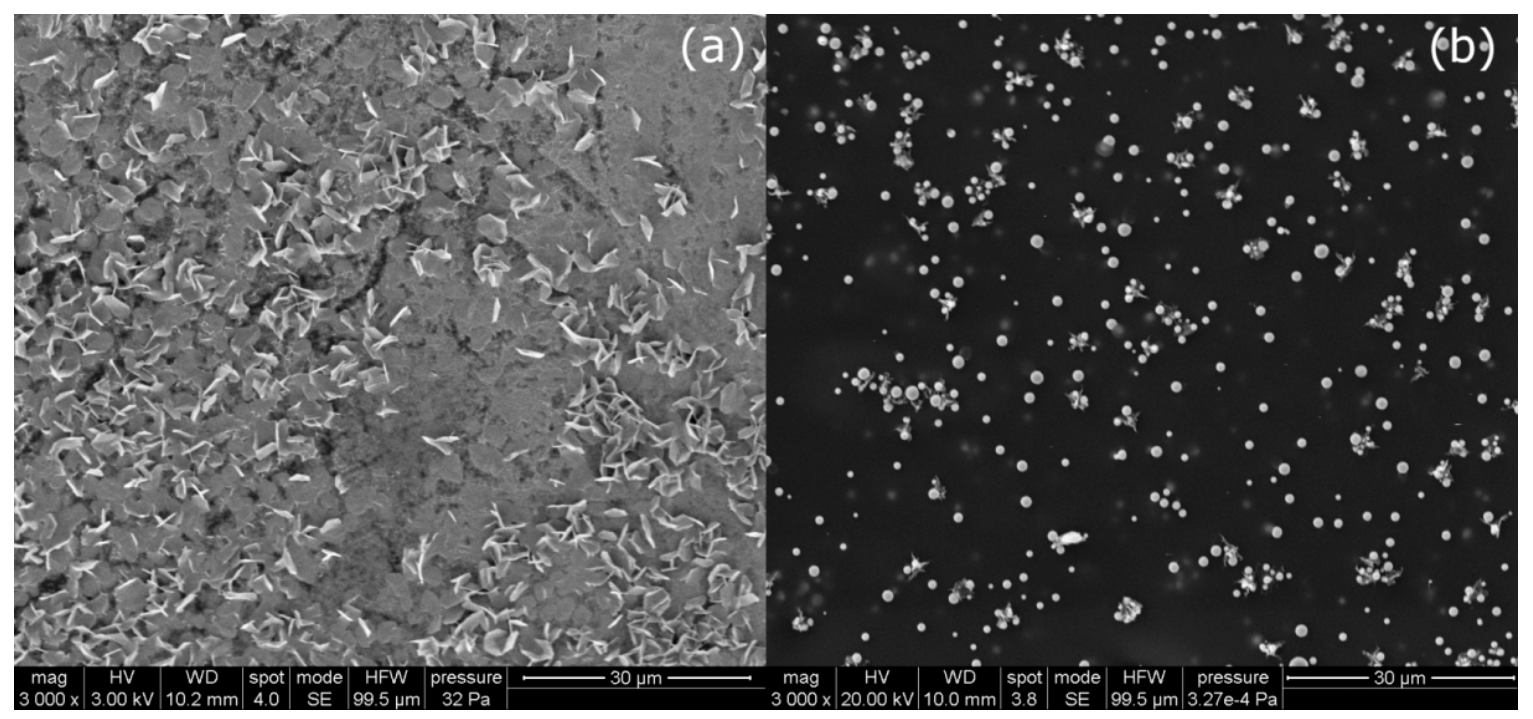

Figure 4. SEM images of Zn/AC-600 (a) and Cu/AC-600 (b).

Table 2. Copper and zinc content in AC samples determined by ICP-MS analysis and nominal content of metals evaluated on the basis of metal chlorides introduced in FA for polymerization.

\begin{tabular}{lccccccc}
\hline & Nominal Content & $\mathrm{Zn/AC-600}$ & $\mathrm{Zn} / \mathrm{AC}-850$ & $\mathrm{Cu} / \mathrm{AC}-850$ & $\mathrm{Zn/AC-600}$ & $\mathrm{Zn} / \mathrm{AC}-850^{*}$ & Cu/AC-850* \\
\hline$\% \mathbf{C u}$ & 3.31 & - & - & 4.68 & - & - & 3.37 \\
$\% \mathbf{Z n}$ & 8.15 & 0.45 & 0.01 & - & 1.05 & 0.01 & - \\
\hline
\end{tabular}

Figure 5 compares XRD patterns of Zn/AC-850*, Zn/AC-600* and Cu/AC-850* sorbents in a $2 \theta$ range of $20-100^{\circ}$. All patterns show the broad signals of the amorphous carbon formed upon pyrolysis treatment of PFA. No peaks associable to Zn were observed for Zn/AC-850* sorbents, which is in agreement with Cesano et al. [10] and with the results of ICP-MS analysis. Small signals assignable to zinc oxide and metallic zinc were detectable in the pattern of Zn/AC-600*, indicating that for lower pyrolysis temperatures some zinc is preserved in the carbon matrix. On the contrary, different peaks with a high intensity, in addition to the carbon background, overlap in the pattern of $\mathrm{Cu} / \mathrm{Ac}-850^{*}$, indicating that copper is present in different forms and oxidation states: $\mathrm{Cu}, \mathrm{CuO}, \mathrm{Cu}_{2} \mathrm{O}$. 


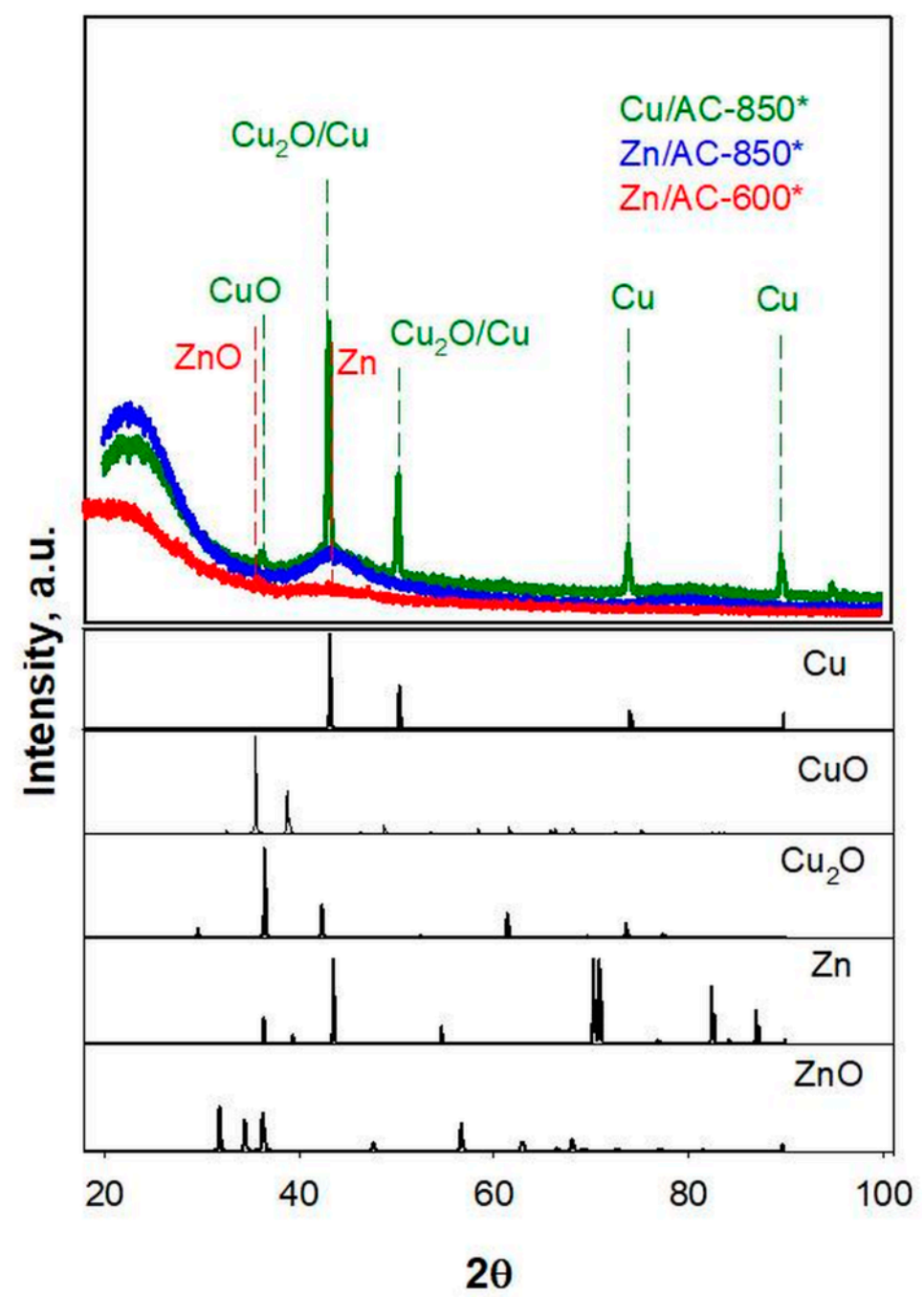

Figure 5. XRD patterns of $\mathrm{Zn} / \mathrm{AC}-850 * \mathrm{Zn} / \mathrm{AC}-600^{*}$ and $\mathrm{Cu} / \mathrm{AC}-850^{*}$. In the lower graph patterns of reference $\mathrm{Zn}$ (PDF 1-1244), ZnO (PDF 36-1451, Cu (PDF 4-836), $\mathrm{Cu}_{2} \mathrm{O}$ (PDF 5-667) and CuO (PDF 45-937) are reported.

In Figure 6 the Raman spectra of $\mathrm{Zn} / \mathrm{AC}-850, \mathrm{Zn} / \mathrm{Ac}-600$ and $\mathrm{Cu} / \mathrm{AC}-850$ samples are reported in the spectral region $1100-1800 \mathrm{~cm}^{-1}$, where carbon and its disorder degree can be identified. The Zn-based sample pyrolyzed at $600{ }^{\circ} \mathrm{C}$ shows more intense bands and all spectra show the typical D and G bands at 1340 and $1590 \mathrm{~cm}^{-1}$, assigned to the presence of amorphous and graphitic carbon respectively [29]. The ratio between the intensities of $\mathrm{D}$ and $\mathrm{G}$ peaks is considered a common measure of the disorder degree. Ordered carbon materials, such as graphite, show a narrow and intense $G$ band and a wide weak $D$ band, whereas a comparable intensity of $D$ and $G$ band indicates quite a high disorder degree. Values of ratio between the intensity of the two peaks $(\mathrm{I}(\mathrm{D}) / \mathrm{I}(\mathrm{G}))$ are very close to 1 for both samples pyrolyzed at $850{ }^{\circ} \mathrm{C}$, while a value of 0.77 was evaluated for $\mathrm{Zn} / \mathrm{AC}-600$. This suggests that a higher pyrolysis temperature partially destroys the graphitic structure that, in turn, is preserved when the temperature is limited to $600{ }^{\circ} \mathrm{C}$.

The porous structure of the AC materials was preliminarily investigated through $\mathrm{N}_{2}$ physisorption at $77 \mathrm{~K}$. The attempts to explore the $10^{-7}-10^{-5}$ bar of relative pressure $\left(\mathrm{p} / \mathrm{p}^{0}\right)$ range for the micropore analysis failed and, for that reason, the investigation was limited to the standard analysis for mesoporous materials. In Figure 7 the adsorption/desorption isotherms are reported for all the samples pyrolyzed under pure helium (a) and for the corresponding samples pyrolyzed under $\mathrm{O}_{2} / \mathrm{He}$ mixture (b). All samples show Type I isotherms, as expected from microporous materials, with a quite well-defined 
plateau, suggesting a small contribution of the external surface area to the adsorption. A lower temperature of pyrolysis reflects in a much higher porosity for Zn-based AC. Nevertheless, an unusual behaviour was observed for all samples except for Zn/AC-600, i.e., adsorption and desorption branches do not converge to form a closed hysteresis, at least in the range of relative pressure explored, in contrast to what observed by Cesano et al. [17]. This effect is even more pronounced when oxygen traces are added in the pyrolysis gas.

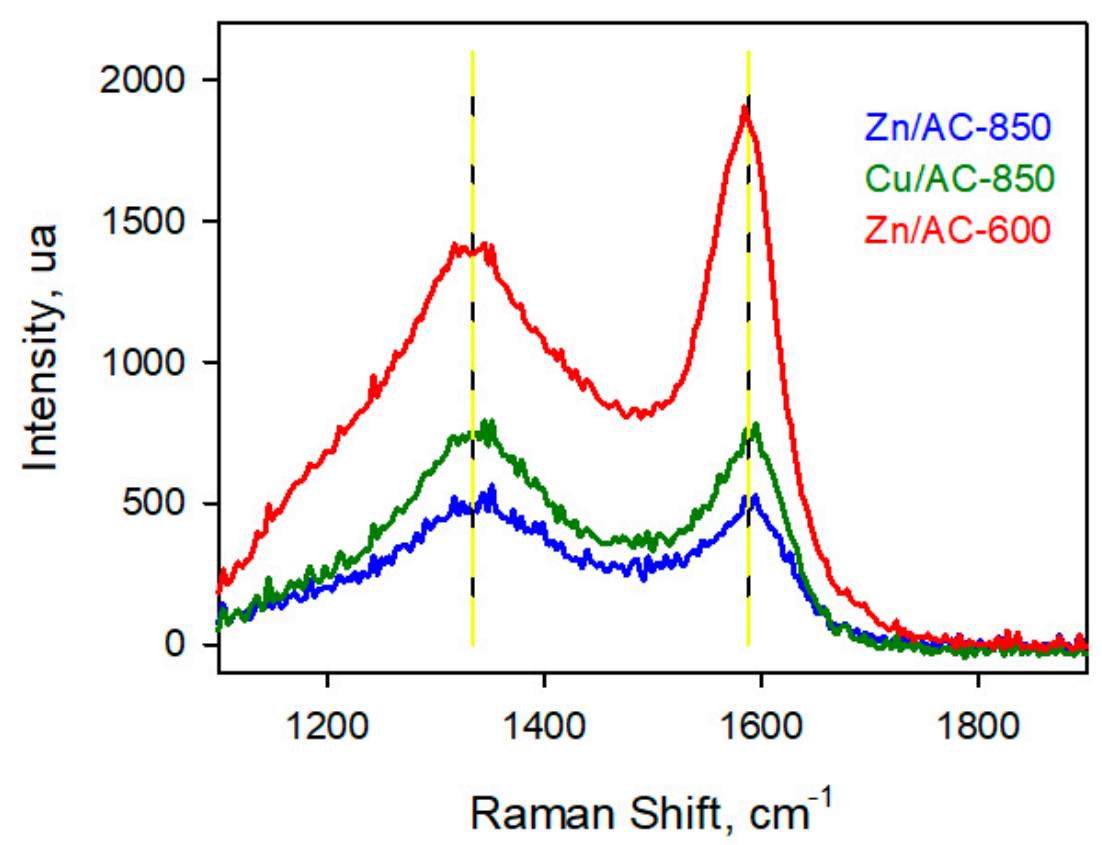

Figure 6. Raman spectra of Zn/AC-850, Zn/AC-600 and Cu/AC-850.

It is reported that this phenomenon is typically associated with the presence of narrow micropores (width $<1 \mathrm{~nm}$ ) and/or to pores with "bottle neck" structure [30-32] and that PFA-derived carbons show bottle-like nano- and micropores with narrow openings connected to larger voids [10].

A similar behaviour was observed for biochar samples and it was explained by the development of a narrow microporosity related to the steam-assisted treatment [30].

Hysteresis phenomena in pore networks consisting of ink-bottle type pores are quite complex and two basic mechanisms of desorption in these pore networks are known, i.e., pore blocking and cavitation. In the case of the former mechanism, desorption from the pore body may occur only after emptying of its neck. In other words, desorption from the neck triggers evaporation in the blocked pore and the vapor pressure of desorption from the pore body depends on the neck size and network connectivity. Moreover, the presence of narrow micropores represents an obstacle to textural analysis by $\mathrm{N}_{2}$ adsorption at $77 \mathrm{~K}$ independently from the occurrence of bottle neck structures. Indeed, diffusion at $77 \mathrm{~K}$ of $\mathrm{N}_{2}$ molecules in pores having a very small size (i.e., $<0.7 \mathrm{~nm}$ ) is intrinsically limited. For these reasons, the BET- $\mathrm{N}_{2}$ area does not generally have the physical significance of an effective area if the carbon is ultra-microporous [22,30]. According to Morishige et al. [32], closure of the hysteresis loop takes place at lower relative pressure when the diameter of the pore neck is $<5 \mathrm{~nm}$, whereas when the diameter of the neck is $>5 \mathrm{~nm}$, the hysteresis loop closes at higher values. As a consequence, since the hysteresis loop did not close at relative $\mathrm{p} / \mathrm{p}^{0}$ pressure as low as 0.1 , the presence of pores with a size well below $5 \mathrm{~nm}$ can be supposed for our carbons. 

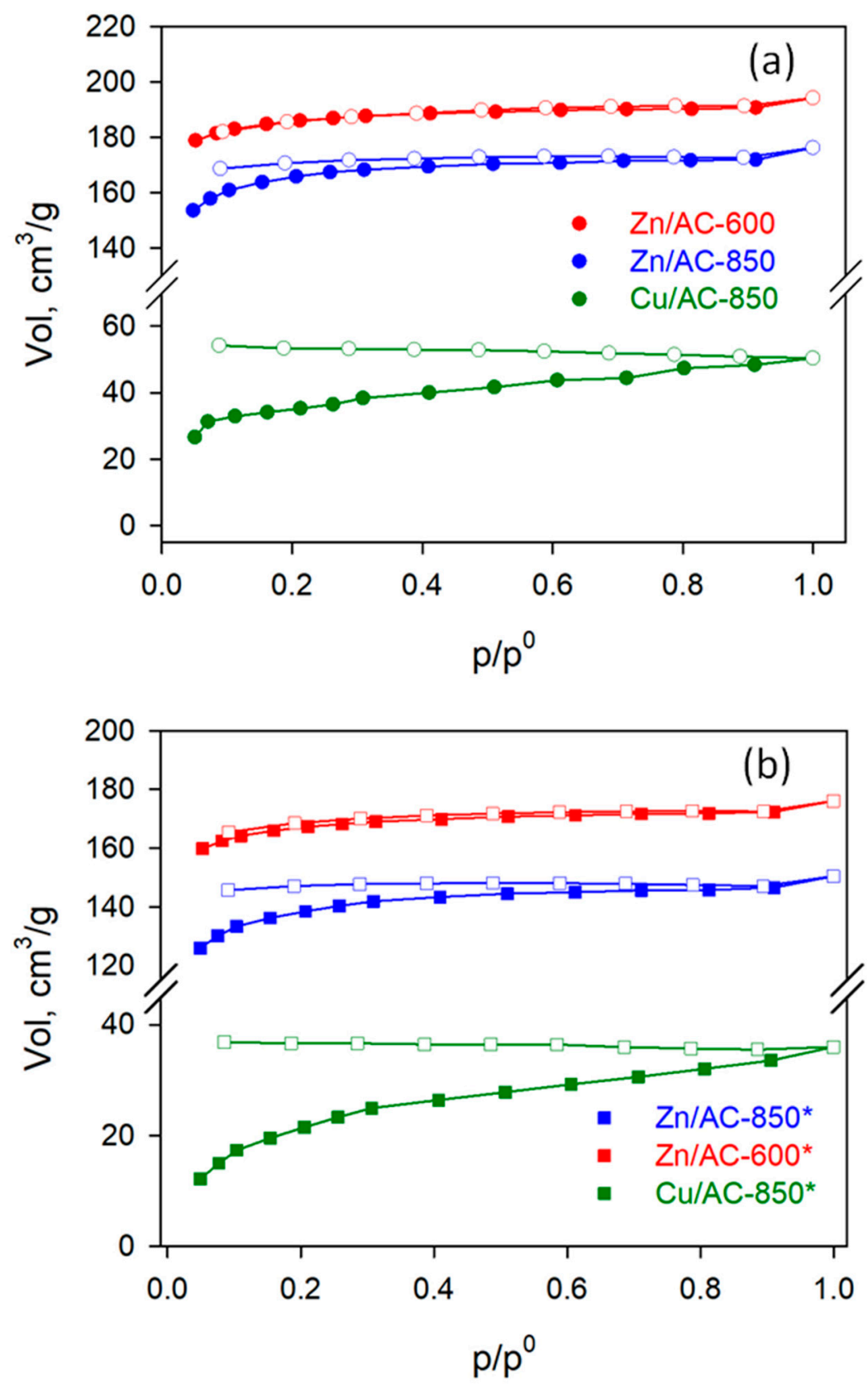

Figure 7. $\mathrm{N}_{2}$ physisorption isotherms at $77 \mathrm{~K}$ for activated carbons pyrolyzed under pure helium (a) and under $\mathrm{O}_{2} / \mathrm{He}$ mixture (b) (closed symbols for adsorption branch, open symbols for desorption branch).

With respect to $\mathrm{N}_{2}$ adsorption at $77 \mathrm{~K}, \mathrm{CO}_{2}$ adsorption at $273 \mathrm{~K}$ results in a higher kinetic energy of probe molecules, which can enter into the narrowest pores, thus overcoming both the aforementioned diffusional problems [7,31] and limitations related to bottle neck pores [33]. At $273 \mathrm{~K}$, the $\mathrm{CO}_{2}$ saturation pressure is quite high, so that the range of $\mathrm{p} / \mathrm{p}^{0}$ is limited to $<0.03$ at sub-atmospheric pressures. The initial part of the adsorption isotherm can thus be determined with much greater accuracy than using $\mathrm{N}_{2}$ at $77 \mathrm{~K}$. In addition, different adsorptives provide complementary information. Finally, it should be noted that the volume of narrow micropores, identified through $\mathrm{CO}_{2}$ adsorption, was found to be linearly correlated with the hydrogen adsorption capacity of various carbon materials by Jordà-Beneyto et al. [5] and by Gadiou et al. [3]. As a consequence, this value can reasonably represent a measure of the $\mathrm{H}_{2}$ storage properties of this activated carbons. 
For this reason, Figure 8 shows $\mathrm{CO}_{2}$ adsorption isotherms at $273 \mathrm{~K}$ on all synthesized AC materials together with the corresponding $\mathrm{N}_{2}$ adsorption isotherms at $77 \mathrm{~K}$.
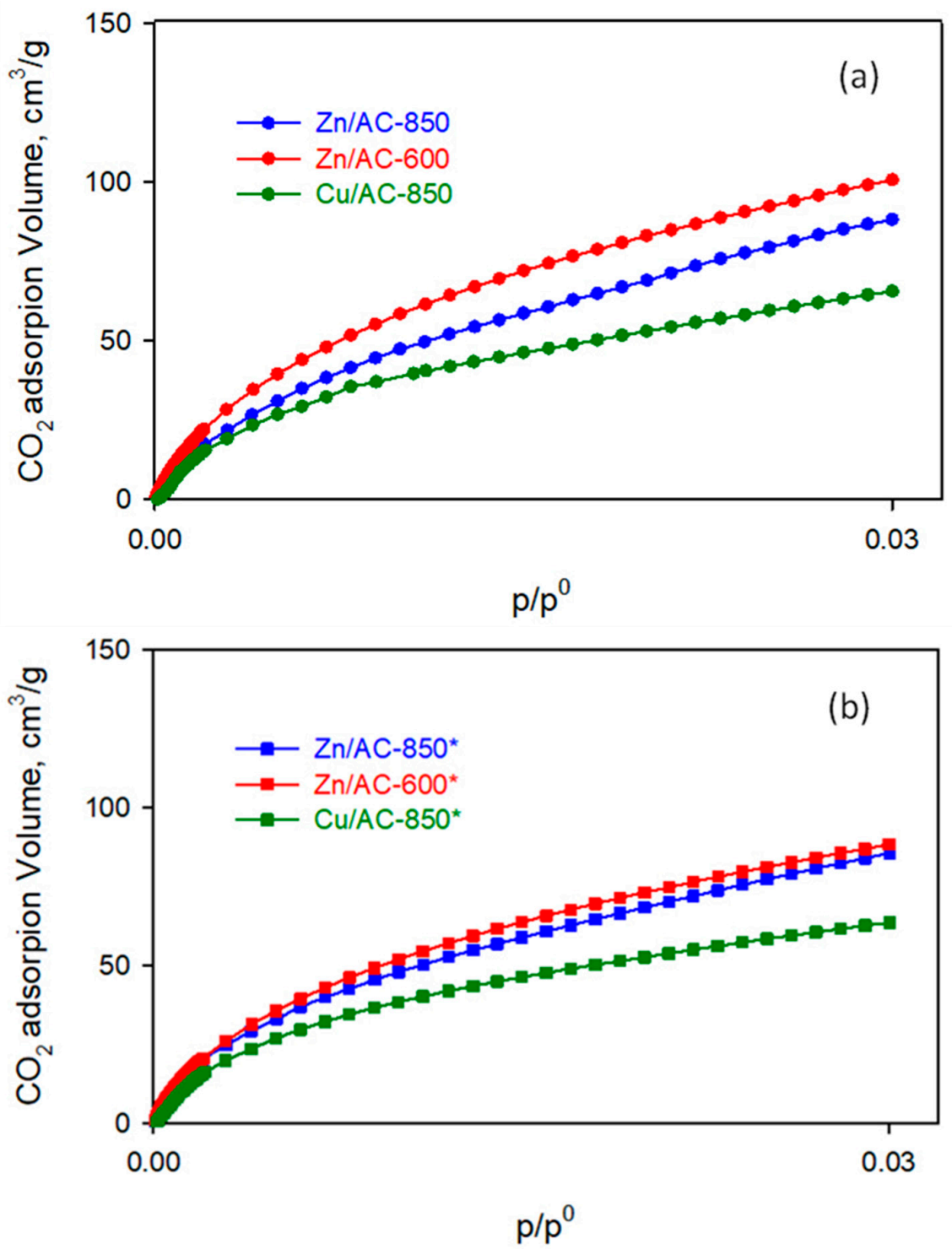

Figure 8. $\mathrm{CO}_{2}$ physisorption isotherms at $273 \mathrm{~K}$ for activated carbons pyrolyzed under pure helium (a) and under $\mathrm{O}_{2} / \mathrm{He}$ mixture (b).

Even if limitations in the absolute pressure bearable by the adsorption instrument make it possible to reach only $\mathrm{CO}_{2}$ relative pressures $<0.03$, this kind of data can usually be modelled with the Dubinin-Radushkevich (DR) equation $[34,35]$. Indeed, the DR model allows the extrapolation (as model parameter) of the total micropore volume of the adsorbents, as reported in Table 3.

Table 3. Textural properties of activated carbons evaluated according to BET, DFT and DR models.

\begin{tabular}{|c|c|c|c|c|c|c|c|}
\hline Sample & $\begin{array}{c}\text { BET } \\
\text { Area } \\
\left(\mathrm{m}^{2} / \mathrm{g}, \mathrm{N}_{2} \text { ads. }\right) \\
\end{array}$ & $\begin{array}{c}D F T \\
\text { Area } \\
\left(\mathrm{m}^{2} / \mathrm{g}, \mathrm{N}_{2} \text { ads. }\right) \\
\end{array}$ & $\begin{array}{c}\text { Total Pore } \\
\text { Volume } \\
\text { (cm } / \mathrm{g}, \mathrm{N}_{2} \text { ads.) }\end{array}$ & $\begin{array}{c}\text { Cumulative } \\
\text { DFT Volume } \\
\text { ( } \mathrm{cm}^{3} / \mathrm{g}, \mathrm{N}_{2} \text { ads.) }\end{array}$ & $\begin{array}{c}\text { DR Micropore } \\
\text { Volume } \\
\left(\mathrm{cm}^{3} / \mathrm{g}, \mathrm{CO}_{2} \text { ads.) }\right.\end{array}$ & $\begin{array}{l}\text { DR Effective Area } \\
\left(\mathrm{m}^{2} / \mathrm{g}, \mathrm{CO}_{2} \text { ads. }\right)\end{array}$ & $\begin{array}{c}\text { Mean Equivalent } \\
\text { Radius } \\
\text { (nm, } \mathrm{CO}_{2} \text { ads.) }\end{array}$ \\
\hline$Z n / A C-600$ & 652 & 698 & 0.296 & 0.268 & 0.368 & 986 & 0.746 \\
\hline $\mathrm{Zn} / A C-600^{*}$ & 618 & 639 & 0.267 & 0.243 & 0.313 & 843 & 0.741 \\
\hline $\mathrm{Zn} / \mathrm{AC}-850^{*}$ & 475 & 493 & 0.219 & 0.209 & 0.296 & 798 & 0.741 \\
\hline$C u / A C-850$ & 123 & 112 & 0.075 & 0.073 & 0.238 & 638 & 0.746 \\
\hline
\end{tabular}


The values of the micropore volume, together with those of the characteristic energy of adsorption (another DR model parameter) were used to calculate the effective surface area [20], pore volume values and mean equivalent radius, in turn reported in Table 3.

In Table 3, the surface area values evaluated for the $\mathrm{N}_{2}$ adsorption branch according to both the BET and DFT models (slit/cylindrical pores model) are also reported together with the total pore volume, estimated at $\mathrm{p} / \mathrm{p}^{0}=0.98$ and the cumulative pore volume calculated by the DFT.

Regardless of the pyrolysis conditions reported in Table 1, all Zn-containing samples show textural parameters that are higher than those reported for similar materials with the same $\mathrm{Zn}$ content [10]. No comparison with literature data can be given for $\mathrm{Cu}$-containing samples due to the novelty in the formulation of these materials.

Values of BET and DFT surface area are quite close for each sample, as well as total pore volume, whereas they are smaller than area and pore volume estimated using the DR model, although only micropore volume was evaluated with this model. Jordà-Beneyto et al. [5] also observed that pitch-based carbon fibres adsorbed $\mathrm{CO}_{2}$ at $273 \mathrm{~K}$ but did not adsorb $\mathrm{N}_{2}$ at $77 \mathrm{~K}$, and this suggests that $\mathrm{CO}_{2}$ adsorption at $273 \mathrm{~K}$ makes it possible to also detect pores not accessible through $\mathrm{N}_{2}$ adsorption at $77 \mathrm{~K}$. Moreover, this supports the choice of the DR model, which is a model suitable for these samples, which are basically microporous with an almost total absence of mesopores.

Nevertheless, although different models were used to estimate the textural parameters of the activated carbons, a unique trend was found for all samples. The results show that $\mathrm{Zn}$-activated PFA derived carbons have a surface area definitively higher than $\mathrm{Cu}$-activated samples, likely due to the quick exothermal polymerization occurring in a few seconds with formation of empty cavities generated by the fast water evaporation. Moreover, surface area increases with both lower pyrolysis temperature and absence of $\mathrm{O}_{2}$ traces in the pyrolysis gas. Therefore, the expected widening of porosity due to the limited burning of carbon did not occur or, if it did occur, it created macropores not evaluated by gas adsorption, likely at the expense of meso and micropores.

$\mathrm{Cu}$-activated carbon shows a much lower surface area and pore volume evaluated according to BET or DFT model, further decreased when oxygen traces are present in the pyrolysis gas, compared to the corresponding Zn-activated samples. Nevertheless, the very large difference observed for both surface area and pore volume using BET or DFT model using $\mathrm{N}_{2}$ physisorption at $77 \mathrm{~K}$ between $\mathrm{Zn}$ - and $\mathrm{Cu}$-activated carbons is strongly reduced when the surface area and volume are estimated according to the DR model applied to data from $\mathrm{CO}_{2}$ physisorption at $273 \mathrm{~K}$.

This is a reasonable indication of the great contribution of narrow micropores in these samples. Indeed, $\mathrm{CO}_{2}$ is able to identify micropores that are completely undetectable using $\mathrm{N}_{2}$ as adsorbent at $77 \mathrm{~K}$, thus incorrectly identifying $\mathrm{Cu}$-activated carbons as materials with a low porosity.

The latter result is in very good agreement with what was observed by Gargiulo et al. [30], who found that the pore volume evaluated by $\mathrm{N}_{2}$ adsorption for bio-chars was lower than that evaluated by $\mathrm{CO}_{2}$ adsorption, suggesting that very narrow micro-pores were not accessible to $\mathrm{N}_{2}$ due to diffusional limitation at $77 \mathrm{~K}$. Furthermore, the value of mean average pore size of about $0.75 \mathrm{~nm}$, estimated according to the DR model, confirms that the diameter of pores or of the pore neck is well below $5 \mathrm{~nm}$, as reported by Morishige et al. [32] and is also in agreement with results of Gargiulo et al. [30], who found a pore size of around $0.6 \mathrm{~nm}$ for their ultra-microporous bio-chars.

In conclusion, the porosimetric results suggest that the two different metal chloride activators lead to carbon materials with rather different textural properties: activated carbons with an almost total dominance of narrow micropores when copper is used as a Lewis acid activator, and activated carbons with meso and micropores when zinc is used as a Lewis acid activator.

\section{Conclusions}

Activated carbons from the pyrolysis of polyfurfuryl alcohol (PFA) were obtained using two different Lewis acids for the activation of FA polymerization: $\mathrm{ZnCl}_{2}$ and $\mathrm{CuCl}_{2}$. The method was 
proposed to produce activated carbons with a macroscopic foamy structure containing suitable metals dispersed into the carbon matrix for applications such as $\mathrm{H}_{2}$ storage or bio-gas purification.

Parameters such as the strength of Lewis acidity of the activator, temperature of polymerization and pyrolysis, and presence of $\mathrm{O}_{2}$ traces in the pyrolysis gas greatly affect the textural properties of the final materials.

PFA formation at $80^{\circ} \mathrm{C}$ promoted by $\mathrm{ZnCl}_{2}$ results in a very foamy material with large cavities and with a large surface area and total pore volume due to the fast and exothermal polymerization producing water vapour that creates a very open structure by quick evaporating. Both $\mathrm{Zn}$ - and Cu-activated PFA have a microporous nature. Nevertheless, the formation of narrow micropores is more favoured when $\mathrm{CuCl}_{2}$ is used to activate polymerization of FA. The much lower evaporation temperature of metallic zinc, formed during the pyrolysis step, with respect to metallic copper, results in an almost total loss of the metal at the higher pyrolysis temperature. On the contrary, copper concentration in the final carbon material is preserved for $\mathrm{Cu}$-activated samples also at high pyrolysis temperature.

In conclusion, all parameters explored can be properly tuned to produce an activated carbon with the desired textural properties and with a three-dimensional structure. The proper choice of this parameters can potentially provide materials suitable to adsorption of different molecules. The prevailing formation of narrow micropores makes these materials particularly suited to $\mathrm{H}_{2}$ storage.

Author Contributions: Conceptualization, N.G. and L.L.; methodology, E.M.C., L.L. and N.G.; investigation, E.M.C. and N.G.; data curation, E.M.C., S.C., D.C. and N.G.; writing-original draft preparation, L.L. and N.G.; writing-review and editing, D.C., S.C. and L.L. All authors have read and agreed to the published version of the manuscript.

Funding: This research received no external funding.

Acknowledgments: The authors are grateful to Luciano Cortese (IRC-CNR) for SEM/EDX analysis and Giuseppe Mocci (ACLabs) for XRD analysis.

Conflicts of Interest: The authors declare no conflict of interest.

\section{References}

1. Esteves, I.A.A.C.; Lopes, M.S.S.; Nunes, P.M.C.; Mota, J.P.B. Adsorption of natural gas and biogas components on activated carbon. Sep. Purif. Technol. 2008, 62, 281-296. [CrossRef]

2. Taguchi, A.; Smått, J.H.; Lindén, M. Carbon monoliths possessing a hierarchical, fully interconnected porosity. Adv. Mater. 2003, 15, 1209-1211. [CrossRef]

3. Gadiou, R.; Saadallah, S.E.; Piquero, T.; David, P.; Parmentier, J.; Vix-Guterl, C. The influence of textural properties on the adsorption of hydrogen on ordered nanostructured carbons. Micropor. Mesopor. Mater. 2005, 79, 121-128. [CrossRef]

4. Rzepka, M.; Lamp, P.; De la Casa-Lillo, M.A. Physisorption of hydrogen on microporous carbon and carbon nanotubes. J. Phys. Chem. B 1998, 102, 10894-10898. [CrossRef]

5. Jordá-Beneyto, M.; Suárez-García, F.; Lozano-Castelló, D.; Cazorla-Amorós, D.; Linares-Solano, A. Hydrogen storage on chemically activated carbons and carbon nanomaterials at high pressures. Carbon 2007, 45, 293-303. [CrossRef]

6. Zubizarreta, L.; Arenillas, A.; Pis, J.J. Carbon materials for $\mathrm{H}_{2}$ storage. Int. J. Hydrogen Energy 2009, 34, 4575-4581. [CrossRef]

7. Lozano-Castelló, D.; Cazorla-Amorós, D.; Linares-Solano, A. Usefulness of $\mathrm{CO}_{2}$ adsorption at $273 \mathrm{~K}$ for the characterization of porous carbons. Carbon 2004, 42, 1233-1242. [CrossRef]

8. Lu, A.H.; Smått, J.H.; Lindén, M. Combined surface and volume templating of highly porous nanocast carbon monoliths. Adv. Funct. Mater. 2005, 15, 865-871. [CrossRef]

9. Zhang, Z.; Jiang, W.; Long, D.; Wang, J.; Qiao, W.; Ling, L. A general silica-templating synthesis of alkaline mesoporous carbon catalysts for highly efficient $\mathrm{H}_{2} \mathrm{~S}$ oxidation at room temperature. ACS Appl. Mater. Interfaces 2017, 9, 2477-2484. [CrossRef]

10. Cesano, F.; Scarano, D.; Bertarione, S.; Bonino, F.; Damin, A.; Bordiga, S.; Prestipino, C.; Lamberti, C.; Zecchina, A. Synthesis of $\mathrm{ZnO}$-carbon composites and imprinted carbon by the pyrolysis of $\mathrm{ZnCl}_{2}$-catalyzed furfuryl alcohol polymers. J. Photoc. Photobio. A 2008, 196, 143-153. [CrossRef] 
11. Wei, X.; Li, H.; Li, Q.; Chen, S. Preparation of nano-ZnO supported on porous carbon and the growth mechanism. Micropor. Mesopor. Mater. 2009, 118, 307-313. [CrossRef]

12. Rather, S.U.; Hwang, S.W.; Kim, A.R.; Nahm, K.S. Room temperature hydrogen uptake of carbon nanotubes promoted by silver metal catalyst. J. Alloys Compd. 2009, 475, 17-21. [CrossRef]

13. Ströbel, R.; Garche, J.; Moseley, P.T.; Jörissen, L.; Wolf, G. Hydrogen storage by carbon materials. J. Power Sources 2006, 159, 781-801. [CrossRef]

14. Balsamo, M.; Cimino, S.; De Falco, G.; Erto, A.; Lisi, L. ZnO-CuO supported on activated carbon for $\mathrm{H}_{2} \mathrm{~S}$ removal at room temperature. Chem. Eng. J. 2016, 304, 399-407. [CrossRef]

15. Balsamo, M.; Cimino, S.; De Falco, G.; Erto, A.; Lisi, L. Synergic effect of mixed ZnO and CuO nanoparticles supported on activated carbon for $\mathrm{H}_{2} \mathrm{~S}$ adsorption at room temperature. Adv. Sci. Lett. 2017, 23, 5879-5882. [CrossRef]

16. De Falco, G.; Montagnaro, F.; Balsamo, M.; Erto, A.; Deorsola, F.A.; Lisi, L.; Cimino, S. Synergic effect of $\mathrm{Zn}$ and $\mathrm{Cu}$ oxides dispersed on activated carbon during reactive adsorption of $\mathrm{H}_{2} \mathrm{~S}$ at room temperature. Micropor. Mesopor. Mater. 2019, 257, 135-146. [CrossRef]

17. Cesano, F.; Rahman, M.M.; Bertarione, S.; Vitillo, J.G.; Scarano, D.; Zecchina, A. Preparation and adsorption properties of activated porous carbons obtained using volatile zinc templating phases. Carbon 2012, 50, 2047-2051. [CrossRef]

18. Sudaryanto, Y.; Hartono, S.B.; Irawaty, W.; Hindarso, H.; Ismadji, S. High surface area activated carbon prepared from cassava peel by chemical activation. Bioresour. Technol. 2006, 97, 734-739. [CrossRef]

19. Landers, J.; Gor, G.Y.; Neimark, A.V. Density functional theory methods for characterization of porous materials. Colloids Surf. A 2013, 437, 3-32. [CrossRef]

20. Medek, J. Possibility of micropore analysis of coal and coke from the carbon dioxide isotherm. Fuel 1997, 56, 131-133. [CrossRef]

21. Marsh, H.; Reinoso, F.R. Activated Carbon, 1st ed.; Elsevier: Oxford, UK, 2006; pp. 87-142.

22. Rouquerol, J.; Rouquerol, F.; Llewellyn, P.; Maurin, G.; Sing, K.S. Adsorption by Powders and Porous Solids Principles, Methodology and Applications; Academic Press: Cambridge, MA, USA, 2013; pp. 321-391.

23. Kobayashi, S.; Busujima, T.; Nagayama, S. A novel classification of Lewis acids on the basis of activity and selectivity. Chem. Eur. J. 2000, 6, 3491-3494. [CrossRef]

24. Dunlop, A.P.; Peters, F.N. The Furans; Reinhold: New York, NY, USA, 1953; pp. 398-399.

25. Wang, H.; Yao, J. Use of poly (furfuryl alcohol) in the fabrication of nanostructured carbons and nanocomposites. Ind. Eng. Chem. Res. 2006, 45, 6393-6404. [CrossRef]

26. Bertarione, S.; Bonino, F.; Cesano, F.; Jain, S.; Zanetti, M.; Scarano, D.; Zecchina, A. Micro-FTIR and micro-Raman studies of a carbon film prepared from furfuryl alcohol polymerization. J. Phys. Chem. B 2009, 113, 10571-10574. [CrossRef] [PubMed]

27. Grabda, M.; Oleszek-Kudlak, S.; Shibata, E.; Nakamura, T. Vaporization of zinc during thermal treatment of $\mathrm{ZnO}$ with tetrabromobisphenol A (TBBPA). J. Hazard. Mater. 2011, 187, 473-479. [CrossRef] [PubMed]

28. Zhang, W.; Tian, Y.; Liu, D.C.; Wang, F.; Yang, B.; Xu, B.Q. Experimental study on the thermal volatilization and condensation of zinc at $10 \mathrm{~Pa}$ and $200 \mathrm{~Pa}$. J. Mater. Res. Technol. 2020, 9, 3590-3597. [CrossRef]

29. Cuesta, A.; Dhamelincourt, P.; Laureyns, J.; Martinez-Alonso, A.; Tascón, J.D. Raman microprobe studies on carbon materials. Carbon 1994, 32, 1523-1532. [CrossRef]

30. Gargiulo, V.; Gomis-Berenguer, A.; Giudicianni, P.; Ania, C.O.; Ragucci, R.; Alfè, M. Assessing the potential of biochars prepared by steam-assisted slow pyrolysis for $\mathrm{CO}_{2}$ adsorption and separation. Energy Fuel. 2018, 32, 10218-10227. [CrossRef]

31. Gargiulo, N.; Imperatore, M.; Aprea, P.; Caputo, D. Synthesis and characterization of a microporous copper triazolate as a water vapor adsorbent. Micropor. Mesopor. Mater. 2011, 145, 74-79. [CrossRef]

32. Morishige, K.; Tateishi, M.; Hirose, F.; Aramaki, K. Change in desorption mechanism from pore blocking to cavitation with temperature for nitrogen in ordered silica with cagelike pores. Langmuir 2006, 22, 9220-9224. [CrossRef]

33. Thommes, M. Physical adsorption characterization of nanoporous materials. Chem. Ing. Tech. 2010, 82, 1059-1073. [CrossRef] 
34. Tascón, J.M.D. Nanoporous carbon fibres by pyrolysis of nomex polyaramid fibres. J. Anal. Calorim. 2005, 79, 529-532. [CrossRef]

35. Echeverría, J.C.; Estella, J.; Barbería, V.; Musgo, J.; Garrido, J.J. Synthesis and characterization of ultramicroporous silica xerogels. J. Non-Cryst. Solids 2010, 356, 378-382. [CrossRef]

(C) 2020 by the authors. Licensee MDPI, Basel, Switzerland. This article is an open access article distributed under the terms and conditions of the Creative Commons Attribution (CC BY) license (http://creativecommons.org/licenses/by/4.0/). 